\title{
A INTERNET COMO FERRAMENTA DE MARKETING NAS BIBLIOTECAS
}

\section{Ângela Maria de Oliveira}

\begin{abstract}
Resumo
As bibliotecas enfrentam a tarefa de atingir os clientes e demonstrar o valor dos seus produtos e serviços, e elas podem utilizar o marketing via internet para alcançar os seus objetivos de atender tanto as suas comunidades como atingir os seus objetivos organizacionais. Por ser um instrumento de comunicação e informação que proporciona facilidade e rapidez no acesso às informações, a internet possibilita novas formas de alcançar os segmentos específicos que a biblioteca pretende atender.
\end{abstract}

Palavras-chave

Marketing na internet; Bibliotecas

\section{INTRODUÇÃO}

Tendo em vista a necessidade de comercialização de seus produtos com os mercados, as empresas estão mais conscientes de que a comunicação com o seu público-alvo é fator decisivo para o sucesso de qualquer negócio.

Há uma série de veículos que permitem uma aproximação das empresas com seus públicos, divulgando características e benefícios dos seus produtos e serviços.
Quem conseguir utilizar um mix de veículos com maior criatividade tem maior possibilidade de chamar mais a atenção do público para seus produtos e serviços.

Cada vez mais as organizações estão reconhecendo a importância da internet como uma ferramenta não somente para obter informações, mas também como um meio utilizado para disseminar informações a respeito de seus produtos e serviços.

$\mathrm{Na}$ biblioteca, a internet poderá ser utilizada em todas as atividades, porém é necessário que os profissionais da infor- 
mação vejam a internet como uma ferramenta de marketing para resolver os problemas dos clientes; conhecer suas necessidades; expor produtos e serviços para esses clientes; e manter um relacionamento estreito com eles.

Entretanto, a evolução da rede, o baixo custo e as vantagens da utilização da internet, podem levar muitos diretores de bibliotecas a acreditar que o simples fato de estarem presentes na rede lhes trazem resultados positivos. Porém, diante dos diversos sites existentes na internet, é importante que esses tenham conteúdos relevantes para o usuário; que sejam amigáveis e tenham qualidade. Onde as páginas mais acessadas na internet, e que prendem mais a atenção dos usuários - são as interativas - onde ele critica, dá sugestões, conversa e sabe que do outro lado existem pessoas interessadas em saber o que ele sente, 0 que ele pensa.

A disponibilização e divulgação dos produtos e serviços aos usuários por meio da internet é cada vez mais necessária como uma maneira de promover a biblioteca. E, se o marketing, via internet, for utilizado de forma eficiente pelas bibliotecas, essas estarão melhores preparadas para enfrentar o futuro e oferecer serviços de alta qualidade, e assim atingir seus objetivos.

Este artigo tem por objetivo examinar algumas das possibilidades das bibliotecas proporcionadas pelo uso da internet como ferramenta de marketing.

\section{EMBASAMENTO TEÓRICO}

\subsection{Marketing}

A American Marketing Association, em 1948, definiu marketing como "execução das atividades de negócio que encaminham o fluxo de mercadorias e serviços, partindo do produtor até os consumidores" (FERNANDES, 1993, p. 177), tendo a visão da organização orientada para vendas, que estimula o interesse do cliente pelos seus produtos e/ou serviços.

Em contrapartida, em 1965, a Ohio State University citada por Cobra (1997, p. 23) entendia marketing como o "processo na sociedade, pelo qual a estrutura da demanda para bens econômicos e serviços é antecipada ou abrangida e satisfeita através da concepção, promoção, troca e distribuição física de bens e serviços", ou seja, uma visão mais ampla do que a definição da American Marketing Association, que só em 1985, fez uma revisão de sua definição de 1948, para enfatizar o que é realizado pelo processo de marketing, assim como é, e o que ele faz. O marketing passou a ser considerado "o processo de planejamento e execução da concepção, preço, promoção e distribuição de idéias, bens e serviços, organizações e eventos para criar trocas que venham a satisfazer objetivos individuais e organizacionais" (BOONE \& KURTZ, 1995, p. 6)

O conceito de marketing, entretanto, não se resume ao campo das instituições lucrativas. Os autores Philip Kotler e Sidney Levy sugeriram, em 1969, que o conceito de marketing deveria abranger também as instituições não lucrativas. (KOTLER \& LEVY, 1969)

Kotler e Armstrong (1998, p.3) vêem o marketing como "um processo social e gerencial através do qual os indivíduos e grupos obtêm aquilo que desejam e de que necessitam, criando e trocando produtos e valores uns com os outros". Do ponto de vista dos autores, é um processo social no qual as empresas preocupam-se com os interesses da sociedade no todo; e um pro- 
cesso gerencial que envolve atividades de análise, planejamento, implementação e controle.

Por outro lado, Las Casas (1991, p.12), ao referir-se ao marketing, discute relações de troca, onde para o autor "Marketing é a área do conhecimento que engloba todas as atividades concernentes às relações de trocas, orientadas para a satisfação dos desejos e necessidades dos consumidores, visando a alcançar determinados objetivos da organização ou indivíduo..."

Essa concepção parte das necessidades e desejos do consumidor e tem como fim a satisfação, tanto do consumidor como da organização.

A assertiva acima evidencia que a preocupação do marketing em relação a um produto e/ou serviço está relacionada com tudo aquilo que cerca e une o produtor e o consumidor, desde a percepção da necessidade de quem consome até a constatação de sua satisfação ou não com o produto ou serviço adquirido.

Entretanto, para muitas pessoas, marketing é, simplesmente, sinônimo de propaganda ou de vendas. Em vendas, os esforços se concentram em convencer que os produtos são bons e desejáveis, ou seja, utilizam-se da venda e da promoção para estimular um volume lucrativo de vendas. Em marketing, no entanto, os esforços se concentram no desenvolvimento de produtos conforme uma demanda existente e também conforme os desejos para quem esses produtos são desenvolvidos, realizando o lucro através da satisfação do cliente.

Para Manzo (1982) o marketing tem seu foco orientado para a satisfação do cliente, isto é, começa e termina no cliente, por implicar em conhecer o que o consumi- dor deseja; implica também em estudar a produção dessa necessidade, produzi-la, distribuí-la, vendê-la ao consumidor e ter o feedback sobre o consumo do produto e/ ou serviço.

\subsection{Internet}

A internet é um conjunto de redes interligadas usada como meio de comunicação entre pessoas de todo o mundo. É também uma poderosa ferramenta para a promoção de produtos e serviços das organizações; e vem sendo utilizada como vantagem competitiva pelas organizações.

Desde o seu nascimento, a partir de um projeto criado em 1969 pelo Departamento de Defesa dos Estados Unidos, que interligava instituições envolvidas em projetos militares, a rede foi crescendo, passando a interligar computadores de universidades por todo o mundo até os dias de hoje, em que interliga computadores de todos os tipos de organizações.

Segundo Silva (2002), várias são as características inerentes ao ambiente web que podem acrescentar vantagens ao desenvolvimento de serviços e produtos pelas unidades de informação. São elas:

- Interatividade e sincronia: Através da web as bibliotecas podem oferecer serviços interativos com respostas imediatas para questões de referência, comentários e sugestões dos usuários.

- Uso do hipertexto e hipermídia: $\mathrm{O}$ hipertexto é uma forma de expressão digital onde a informação está organizada de forma associativa. As palavras marcadas no texto permitem acesso a outros documentos relacionados com o assunto em ques- 
tão. Além do hipertexto, tem a hipermídia. Através da hipermídia, pode-se unir texto, som e imagem em um mesmo documento.

- Rapidez/agilidade: A possibilidade de acessar os produtos e serviços de biblioteca através da web permite que várias bases de dados possam ser acessadas simultaneamente, diminuindo o tempo a ser gasto pelos usuários.

A seguir, serão descritas algumas ferramentas disponíveis na internet:

- Correio eletrônico (e-mail) - Serviço que permite enviar mensagens através de computadores e de outros dispositivos de comunicação das redes. Podese anexar a mensagem qualquer tipo de arquivo. Para utilizá-lo, além do acesso à internet e de um software adequado, é necessário conhecer o endereço eletrônico da pessoa ou empresa para quem se deseja enviar a mensagem.

- TELNET - Serviço que permite a um utilizador ligar-se a um computador da Internet e passar a trabalhar nele como se o seu computador local fosse um terminal do outro terminal virtual.

- Protocolo de transferência de arquivos -FTP - Serviço que permite a transferência (envio e recepção) de arquivos entre dois computadores. Podendo o arquivo ser um texto, uma planilha, som musical, dentre outros.

- Foruns de discussão (NEWS GROUPS) - Esse serviço permite que os utilizadores possam lançar temas de discussão, que vão sendo desenvolvidos por quem quiser e fizer parte do grupo. As mensagens são enviadas a um servidor, discriminando-se o tema. $O$ servidor organiza as mensagens em sequência, que poderá ser visualizada e acessada por qualquer pessoa.

- Lista de mala direta ( mail-list) - sistema que utiliza o correio eletrônico como mecanismo de divulgação e distribuição de informações. Para participar, o usuário precisa cadastrar-se em um site que administra listas, registrando seu endereço do correio eletrônico em uma mala direta. Toda mensagem recebida pelo site é automaticamente distribuída a todos os participantes da lista da mala direta.

- Bate-papo ou IRC ( Internet Relay Chat) os " chats" - são sistemas de comunicação da internet que permitem uma comunicação em grupo sobre determinado tema. Os participantes da conversa precisam estar conectados simultaneamente na internet, pois trocam mensagens em tempo real.

\section{A INTERNET COMO FERRAMENTA DE MARKETING}

A internet é uma ferramenta de comunicação poderosa que pode tornar mais rápida e eficaz a comunicação interna entre os diversos setores da biblioteca; com a sua comunidade de usuários; e a divulgação dos seus serviços e produtos. Além da redução dos custos em publicidade e comunicação.

Em relação ao custo do marketing via internet Rosa, (1999) (citado por LATRES e ALBAGLI, 1999,p. 87) salienta que

A internet é uma mídia barata e interativa [...] Pelo preço de uma página inteira em revistas semanais de grande circulação no Brasil pode-se construir uma home page de 300 páginas de informação. 
A internet provê acesso a uma quantidade gigantesca de informações científicas, culturais, artísticas, de lazer, em tempo real, onde tempo e distância já não são mais fatores significativos, sendo considerados obstáculos sem importância para a conveniência do usuário.

Entre os impactos da Internet nas bibliotecas e serviços de informação, podese citar: enorme facilidade de acesso a documentos eletrônicos disponíveis na rede; número de usuários acessando diretamente a informação desejada sem a intermediação da biblioteca e a ausência de contato direto com os usuários. A biblioteca pode assinar listas de discussão para todos os professores e imprimir as discussões da lista, fazendo-a circular entre os interessados; pode-se usar a conta de correio eletrônico da biblioteca como uma caixa postal coletiva, para solicitação e/ou oferecimento de pesquisa bibliográfica, colaboração em projetos desenvolvidos em parceria, consultas e esclarecimentos de dúvidas.

As bibliotecas têm aproveitado de várias formas a potencialidade da internet para disponibilizar produtos e serviços aos usuários. Essa assertiva pode ser comprovada através da pesquisa de Oliveira (2001) que verificou se os gerentes das Bibliotecas Públicas Universitárias do Estado do Paraná estavam utilizando a internet como ferramenta de marketing. Dentre os resultados pode-se mencionar:

a) entre os sujeitos pesquisados que afirmaram que a internet tem possibilitado uma melhor aplicação de marketing em suas bibliotecas de atuação $8(22,9 \%)$ utilizam a home page da biblioteca. Eis algumas afirmações:

- a biblioteca disponibiliza seu acervo, fazendo com que os usuários, até mesmo de outras instituições, possam consultálo.

- possibilita que os usuários conheçam melhor o acervo, sem precisarem de deslocarse até a biblioteca.

b) para 7 (20\%) dos sujeitos pesquisados, a internet é apenas uma ferramenta para recuperação de informação e acesso a e-mail. Algumas afirmações dos sujeitos pesquisados comprovam esta afirmativa:

- com os sites fica cada vez mais fácil de conseguir periódicos;

- embora a maior parte dos alunos tenha internet nas suas casas, quando eles pesquisam na biblioteca têm noção maior das fontes de informação e se interessam pela forma de busca para encontrar a informação de que desejam;

- os usuários podem acessar os seus e-mails.

c) Para quatro $(11,4 \%)$ dos sujeitos pesquisados, a internet é um veículo de comunicação que pode estreitar as relações biblioteca/usuário. Algumas afirmações:

- a internet é a rede mundial de computadores integrando pessoas e empresas no mundo inteiro. A tecnologia tem permitido à universidade e, conseqüentemente, à biblioteca, a qual se insere em sua estrutura, prover serviços e 
produtos para uma clientela específica, através da preservação, disseminação e aplicação de novos conhecimentos. Isso poderá mais tarde, transformar a informação que dominamos em um negócio lucrativo agregando-lhe valor monetário.

- a internet agiliza a informação e mostra nossos produtos e serviços.

Os resultados da pesquisa mostraram que $34,3 \%$ dos sujeitos pesquisados estavam utilizando a internet para divulgar seus produtos e serviços.

A consulta ao acervo da biblioteca via internet é uma prática que possibilita ao usuário agilidade e rapidez na localização da informação, podendo estar em sua casa ou em qualquer outro local. Permitindo que, antes de ir à biblioteca, o usuário já tenha verificado se a mesma possui a informação e/ou documento desejado.

Oliveira e Bertholino (2000) ao identificar produtos e serviços de referência disponíveis nas home pages das bibliotecas universitárias da Região Sudeste do Brasil, verificou que todas as bibliotecas analisadas (12 públicas e 11 privadas) disponibilizam em suas home pages recursos informacionais que podem responder as questões dos usuários. Algumas bibliotecas podem responder tanto questões simples como questões complexas, com interatividade ou não; e outras, responder apenas as questões simples e sem interatividade. Isso vem demonstrando que, a partir do surgimento da internet, as bibliotecas estão disponibilizando em suas home pages seus serviços e produtos para consulta remota.
Porém, ao disponibilizar sua home page na internet, a biblioteca necessita de tomar algumas precauções, pois, ao verem a home page da biblioteca na internet, os usuários entendem que, a partir daquele momento, a biblioteca coloca-se à disposição para um diálogo permanente.

No entanto, é importante alertar que se este canal de diálogo deixar de existir ou for ineficiente, poderá criar neles uma descredibilidade na imagem [...] [da biblioteca], gerando muitos problemas. ( $\mathrm{NUCl}$, 1997, p. 83)

Entre os serviços básicos viabilizados pela internet estão: correio eletrônico, transferência de arquivos, disseminação e recuperação da informação. Sendo o correio eletrônico o serviço mais difundido, permitindo comunicação rápida entre pessoas independentemente de sua localização geográfica, só precisando ser usuário da rede e conhecer o endereço eletrônico das pessoas, das instituições ou das empresas para os quais se pretende enviar as mensagens. Quanto à disseminação e recuperação da informação, a internet torna-se um complemento dos materiais bibliográficos disponíveis, agilizando o processo de localização da informação.

Para Catarino (1999, p. 25) “... o profissional da informação não deve apenas usufruir dos recursos já disponíveis na rede, mas sim, disponibilizar produtos na rede". Segundo a autora são várias as possibilidades, entre elas: "construir home page; administrar listas de discussão; elaborar apontadores de informações em diversas áreas de especialidades; filtrar os documentos disponíveis na rede e divulgá-los para seus usuários; participar de projetos de bibliotecas, entre outras".

A internet é uma ferramenta que as 
bibliotecas poderão utilizar cada vez mais para realizar o marketing, pois, o marketing via internet tem algumas vantagens, entre elas:

a) comodidade e conforto para acesso a produtos e/ou serviços 24 h por dia;

b) capacidade de descrição dos produtos e serviços muito maior que as outras mídias;

c) agilidade no atendimento aos clientes;

d) maior interação com os seus usuários;

e) atendimento personalizado.

A IMSC- Interactive Marketing Shopping \& Communications , citado por Baptistella (1999, p. 58), cita alguns de seus princípios de marketing na internet. São eles:

- rapidez e profissionalismo: os sites devem ser visualmente ricos e de rápida e fácil navegação;

- objetividade e originalidade: os sites devem ir direto ao ponto desejado atingindo o público alvo.;

- interatividade: permite ao leitor escolher onde ir e interagir com a empresa;

- humano: linguagem fácil de entender.

\section{CONCLUSÃO}

Várias são as possibilidades da biblioteca utilizar a internet como ferramenta de marketing. Podendo divulgar seus produtos e serviços; obter informações sobre seus clientes para assim ter uma melhor adequação às expectativas do mercado e desenvolvimento de novos produtos; melhorar a interação biblioteca-cliente através de um serviço de atendimento diferenciado. Basta saber usufruir desta ferramenta.

\section{REFERÊNCIAS}

BAPTISTELLA, M.M.T. Comércio eletrônico: algumas maneiras de disponibilizá-lo com credibilidade e segurança. Universitária - Revista da Fac. Integradas de Toledo, Araçatuba, v.2, n. 2, p. 58, 1999.

BOONE, L.E. ; KURTZ, D.L. Marketing contemporâneo. 8. ed. Rio de Janeiro: LTC, 1995. 564 p.

CATARINO, M.E. Internet: ferramenta de trabalho para os profissionais de informação. In: SIMPÓSIO INTERNACIONAL DE BIBLIOTECONOMIA " PROF. DR. PAULO TARCISIO MAYRINK, 2., 1999, Marília. Anais... Marília: UNESP, 1999. p.19-27.

COBRA, M. Marketing básico: uma abordagem brasileira. 4. ed. São Paulo: Atlas, 1997. $552 p$.

FERNANDES, A. R.M. Marketing aplicado a Biblioteconomia. In: SILVEIRA, A.; AMARAL, S. A. do. Marketing em unidades de informaÇão: estudos brasileiros. Brasília : IBICT, 1993. p.77-190.

KOTLER, P. : ARMSTRONG, G. Principios de marketing. 7. ed. Rio de Janeiro: Prentice-Hall do Brasil, 1998.

KOTLER, P.;LEVY,S.J. Broadening the concept of marketing. Journal of Marketing, v. 33, n. 
1, p. 10-15, jan. 1969.

LAS CASAS, A. L. Marketing de serviços. São Paulo : Atlas, 1991.

LASTRES, H. M. M.; ALBAGLI, S. (orgs.). Informação e globalização na era do conhecimento. Rio de Janeiro: Campus, 1999. 318p.

MANZO, J. M. C. Marketing : uma ferramenta para o desenvolvimento Rio de Janeiro : Zahar, 1982.

NUCl, E. Promoção dos serviços com base em tecnologia. Campinas, 1997. 103f. Dissertação (Mestrado em Biblioteconomia) Pontifícia Universidade Católica de Campina, Campinas, 1997.

OLIVEIRA, A. M. de. Conhecimento e percepão de marketing: gerentes das bibliotecas universitárias públicas do Estado do Paraná, Brasil. 2001. 156f. Dissertação (Mestrado em Biblioteconomia e Ciência da Informação), Pontifícia Universidade Católica de Campinas, 2001.

OLIVEIRA, N.M.; BERTHOLINO, M.L.F. Usuários remotos e serviços de referencia $(S R(s))$ disponíveis na home pages das bibliotecas universitárias. In: SEMINÁRIO NACIONAL DE BIBLIOTECAS UNIVERSITÁRIAS, 11., 2000, Florianópolis. Anais... Florianópolis: UFSC, 2000. 1 CD-ROM

SILVA, E. P. da. Serviço on line de referência e informação. Disponível em: <http:// www.referenciaonline.hpg.ig.com.br $>$ Acesso em: 20 mar 2002.

\section{Angela Maria de Oliveira}

Bibliotecária da Universidade Estadual de Ponta Grossa. Mestre pelo Curso de PósGraduação em Biblioteconomia e Ciência da Informação da Pontifícia Universidade Católica de Campinas

e-mail: amolivei@uepg.br

\section{Title}

The internet as a tool of marketing for libraries

\section{Abstract}

Libraries face the task of reaching customers and demonstrate the value of their products and services. They can use marketing via internet to reach the objectives of serving their communities as well as to reach their organizacional objectives. As an instrument of communication and information that provides easy and quick information access, the Internet facilitates new forms to reach the specific segments the library wants to serve.

\section{Keywords}

Marketing on the Internet; Library; Marketing; Internet

\section{Titulo}

La Internet como herramienta de marketing en las bibliotecas

\section{Resumen}

Las Biliotecas enfrentan la tarea de atingir los clientes y demostar el valor de sus productos y servicios, y ellas pueden utilizar el marketing vía internet para alcanzar sus objetivos de atender tanto sus comunidades como atingir sus objetivos organizacionales. Por ser un instrumento de comunicación e información que proporciona facilidad y rapidez en el acceso a las informaciones, la internet posibilita nuevas formas de alcanzar los segmentos específicos que la biblioteca pretiende atender.

\section{Palabras-clave}

Marketing en la Internet; Bibliotecas

Artigo recebido em: 05/08/2002 